\title{
A PROTEÇÃo GEOGRÁFICA DO CHÁ DE DARJEELING: DESAFIOS \\ ENFRENTADOS E OS RESULTADOS.
}

\section{LA PROTECTION DES INDICATIONS GÉOGRAPHIQUES DARJEELING THÉ: LES DÉFIS ET LES RÉSULTATS}

\author{
DEMETRIUS NICHELE MACEI ${ }^{1}$ \\ DIOGO RAUSIS ${ }^{2}$ \\ FABRICCIO PETRELI TAROSSO ${ }^{3}$
}

\begin{abstract}
RESUMO
O chá indiano da região de Darjeeling é um dos mais apreciados do mundo. Sua produção requer uma série de fatores que envolvem desde o clima da região até a perícia na sua colheita. A tradição do seu plantio é centenária e repassada para as gerações futuras, garantindo desta forma o ciclo de produção do chá mais cobiçado do mundo. Não é só a especificidade da produção que torna o chá de Darjeeling especial, mas toda uma gama de distinção entre o clima, o solo e a planta do chá em si. A fama internacional do chá de Darjeeling trouxe a necessidade de preocupar-se com a proteção da marca, por meio do registro de Indicador Geográfico. A preocupação é oriunda do uso da palavra e do logotipo "Darjeeling" por empresas estrangeiras, sendo em alguns casos até registrados, e protegidos como marca, nas suas legislações pátrias. O governo
\end{abstract}

\footnotetext{
${ }^{1}$ Pós-doutorado na Faculdade de Direito do Largo São Francisco (USP). Doutor em Direito Tributário pela Pontifícia Universidade Católica de São Paulo (2012). Mestre em Direito Econômico e Social (2004) e Especialista em Direito Empresarial (2000), ambos pela Pontifícia Universidade Católica do Paraná, Bacharel em Direito pela Universidade Federal do Paraná (1994). Professor de Direito Tributário na graduação, especialização, mestrado e doutorado na Faculdade de Direito Curitiba (UNICURITIBA)

2 Advogado. Mestrando em Direito Empresarial e Cidadania pelo Centro Universitário Curitiba (UNICURITIBA), linha de pesquisa (2) Atividade Empresarial e Constituição: inclusão e sustentabilidade; Pós Graduado em Sociologia Política (Lato Sensu) pela Universidade Federal do Paraná - UFPR; Pós Graduado em História Contemporânea e Relações Internacionais (Lato Sensu) pela Pontifícia Universidade Católica do Paraná - PUC/PR; Pós Graduado em Relações Internacionais e Diplomacia (Lato Sensu) pelo Centro Universitário Curitiba (UNICURITIBA); Possui Graduação em Direito pela Faculdade de Direito de Curitiba (UNICURITIBA). E-mail: rausis.diogo@ hotmail.com

3 Advogado. Mestrando em Direito Empresarial e Cidadania pelo Centro Universitário Curitiba (UNICURITIBA; Graduado em Direito pela Pontifícia Universidade Católica do Paraná - PUC-PR (2001); Pós graduação "lato senso" em Direito Processual Tributário pelo Centro Universitário Positivo UNICENP (2003); email: fabricciotarosso@gmail.com
} 
indiano por meio de lei criou A Diretoria do Chá, afim de proteger um dos seus mais importantes produtos de exportação, no âmbito do comércio internacional. O objeto do presente estudo é verificar como o uso da palavra e o registro do logotipo "Chá de Darjeeling" são tratados por países desenvolvidos - no estudo específico, Japão e França-quando se trata de interesses de empresas da sua nacionalidade, em relação à proteção de marcas de empresas estrangeiras, reconhecida mundialmente por ser um Indicador Geográfico.

Palavras-Chaves: Indicador Geográfico; Organização Mundial do Comércio; Acordos TRIPS; Propriedade Intelectual.

\section{RÉSUMÉ}

Le thé indien de la région de Darjeeling est l'un des plus appréciés dans le monde. Sa production nécessite beaucoup de facteurs qui impliquent du climat à l'expertise de leur récolte._La tradition de la plantation de son centenaire et est transmis aux générations futures, assurant ainsi le cycle de production des plus convoité au monde du thé.Ne seulement pas la spécificité de la production qui rend le thé Darjeeling spécial, mais toute une gamme de distinction entre le climat, le sol et plante le thé lui-même._Le mondialement célèbre thé Darjeeling a apporté la nécessité de se soucier de la protection des marques par l'enregistrement de I'indicateur Géographique._Le problème vient de l'utilisation du mot et le logo "Darjeeling" par des sociétés étrangères, et dans certains cas même enregistrée et protégée en tant que marque dans leur législation patries._Le gouvernement indien à travers la loi a créé le Conseil du thé afin de protéger un de ses produits d'exportation les plus importants dans le commerce international. L'objet de cette étude est de voir comment l'usage des mots et l'enregistrement du logo "Darjeeling" sont gérées par les pays développés - en particulier étude, le Japon et la France, quand il s'agit d'intérêts commerciaux de leur nationalité en ce qui concerne la protection des marques de sociétés étrangères, ont reconnu dans le monde entier pour être un Indicateur Géographique.

Mots clés: Indicateur Géographique ; Organisation Mondiale du Commerce ; Accords ADPIC; Propriété Intellectuelle 


\section{INTRODUÇÃO}

O chá de Darjeeling é um dos produtos mais apreciados em toda Europa, sendo produzido e exportado há mais de cento e cinquenta anos. Países como Japão, Rússia, Estados Unidos, Inglaterra, França, Alemanha e Holanda, estão como seus maiores consumidores. Apesar da sua escala produtiva ser de pequeno porte, se for levado em consideração sua fama mundial, o produto é altamente requisitado pelo seu aroma e sabor, distinto de qualquer outro produto do gênero. Sua distinção está diretamente ligada a fatores climáticos, alteração química da planta e do solo, devido sua produção estar localizada em um ambiente montanhoso.

Nesse panorama, o presente estudo tem como objetivo demonstrar em seu primeiro capítulo, sua especificidade única, pelo seu caráter distintivo, e todo o seu mecanismo de produção. É descrito o ambiente, no qual a planta é semeada, levando em consideração sua localização geográfica, fator importante para consistência do sabor. As características químicas da planta também são mencionadas, por serem eles, outro fator decisivo na composição do aroma e textura. O modo centenário de produção, que vai desde a colheita ao modo de preparo do chá, é o diferencial para a manutenção da qualidade do produto, que será exportado.

O segundo capítulo, trata da preocupação do governo indiano de proteger o chá de Darjeeling, por meio de um aparato legal. O esforço para estruturar um sistema que garanta internamente a produção de boa qualidade do chá, fiscalizando sua produção na região de Darjeeling, e sua exportação, garantindo a integridade do produto final. É abordada a legislação que garante a proteção da marca "Chá de Darjeeling" no âmbito nacional como no internacional, pelo fato do chá ser um Indicador Geográfico.

O terceiro e último capitulo, traz à apreciação casos de uso não autorizado, por empresas japonesas e francesas, da palavra e logotipo "Darjeeling". Mesmo a marca sendo devidamente registrada e reconhecida mundialmente, o uso da palavra "Darjeeling" e o logotipo têm sido alvo de inúmeros "ataques" comerciais. A falta de uma legislação concisa com as regras internacionais de proteção de patentes e marcas tem levado ao governo indiano a disputas judiciais, sem ter um efetivo amparo legal nos países citados. Tal situação trouxe um desconforto financeiro, expondo as indústrias de chá da região de Darjeeling a um cenário de insegurança jurídica, maximizado pela falta de complacência legal (descaso em algumas situações) dos países mencionados. Por fim, o presente estudo tem como intuito a reflexão do instituto de proteção e de marcas e patentes no cenário do comércio internacional, no que concerne ao aparato técnico jurídico de proteção e efetivação entre países desenvolvidos e em desenvolvimento.

\section{O CHÁ DE DARJEELING COMO INDICADOR GEOGRÁFICO}

A indústria do chá na Índia está concentrada no setor privado, sendo regulamentada pelo Estado por meio do Ministério do Comércio, desde 1933, que sob forma de decretos, acabaram por culminar na Lei do Chá. A lei foi promulgada em 1953 permitindo a criação da Diretoria do Chá ${ }^{4}$, constituída em 01 de abril de 1954.

\footnotetext{
${ }^{4}$ A Diretoria do Chá (The Tea Bord) é formado por Conselho, cujo funcionamento, está diretamente ligado ao Governo Central, como um órgão estatutário, no âmbito do Ministério do Comércio. Sendo constituído por 31 (trinta e um membros) incluindo o presidente, composto por membros do Parlamento, produtores, comerciantes de chá, consumidores, sindicatos dos produtores de chá e representantes das principais regiões produtoras de chá, reconstituído a cada três anos. O Conselho é formado por 6 (seis)
} 
O esforço da Índia de manter uma qualidade impecável na produção do chá de "Darjeeling" está nos índices de produção, os quais apontam uma produção total de 846 milhões $\mathrm{kg}$ ao ano (sendo a Índia uma dos maiores produtoras exportadoras de chá do mundo (em 2002 era responsável por $31 \%$ do fornecimento deste produto em escala global). Entre os demais chás produzidos na Índia, "Darjeeling" oferece uma qualidade superior aos demais produtos ofertados no país, pela sua característica distinta de sabor, que resultou na reputação global de mais de um século.

O que distingue o chá de "Darjeeling" dos demais produzidos na Índia, transformando-o em um produto excepcional e distintivo são três fatores: a) a origem geográfica; b) a planta do chá; c) e o modo de produção.

A qualidade do chá está diretamente ligada ao seu clima locacional, condições do solo e altitude. Os jardins de chá estão localizados em altitudes que variam de $600 \mathrm{a}$ 2.250 metros acima do nível do mar ${ }^{5}$. Devido a essa localização, a baixa temperatura constante, variação térmica entre $5^{\circ}$ e $30^{\circ}$, faz com que a taxa de metabolismo (fotossíntese) da planta do chá tenha um baixo de crescimento das folhas, aumentando a concentração das características químicas naturais. Outro fator agroclimático que contribui para o desenvolvimento único da planta é a presença dos declives, responsáveis pela drenagem natural e a intermitência entre sol e nuvens.

A planta do chá "Darjeeling", botanicamente chamada de camellis sinensis, é uma espécie da família theacease, que tem como característica estrutural básica, o crescimento lento e resistente, podendo atingir $2,5 \mathrm{~m}$ altura, contendo folhas perene e multicaule. A planta de Darjeeling tem um crescimento demorado, variando entre 6 a 8 anos para atingir a maturidade, só sendo viável para uma colheita rentável o término desse período. Outra característica que distingue o chá indiano é sua capacidade de suportar invernos rigorosos, secas prolongadas e as altitudes da região de Darjeeling. A combinação entre a química do solo - ricos em minerais devido à região montanhosa- e o genes da planta endérmica ${ }^{6}$, faz com que o aroma e o sabor do chá cultivado na região de Darjeeling sejam únicos; pesquisas feitas com algumas variedades de chá cultivadas em outras regiões da Índia, com condições agroclimáticas distintas, não produzem o mesmo aroma e sabor produzido em Darjeeling.

A produtividade do chá da região de Darjeeling é muito inferior a de outras regiões, a área de plantio tem apenas 87 plantações certificadas, não havendo

comissões permanentes, sendo elas: a) Comitê Executivo; b) Comitê de Promoção de Chá; c) Comissão de Trabalho e Bem Estar; d) Comitê de Desenvolvimento; e) Comitê de Licenciamento para o Norte da Índia; Comitê de Licenciamento para o Sul da Índia.

${ }^{5}$ As plantações de chá Darjeeling localizam-se nos sete vales das montanhas de Darjeeling, próximas dos Himalaias e o Kanchenjunga, o terceiro pico mais alto do mundo. O vento frio dos Himalaias que sopra nos sete vales, a várias temperaturas durante o ano, é um dos elementos que contribui para o sabor único do Darjeeling. Além disso, as montanhas de Darjeeling ficam cobertas de bruma durante a noite, provocando a condensação das moléculas de água da atmosfera que se depositam suavemente nas folas de chá de Darjeeling, hidratando-as. As montanhas de Darjeeling registam grande precipitação anual (entre 2.000 e 4.000 milímetros por ano) e recebem apenas 4 a 5 horas de luz solar durante ímetros por ano) e recebem apenas 4 a 5 horas de luz solar durante cerca de 180 dias por ano. Esses fenômenos naturais contribuem significativamente para o desenvolvimento do sabor e das características ímpares do chá do Darjeeling.

${ }^{6}$ Estão presentes no chá Darjeeling os componentes químicos óxido de linalool (I,II,III e IV), em concentrações muito elevadas, geraniol, salicilato de metilo, álcool benzílico, 2-feniletanol, dihidroactinidiolida, ácido hexanótico, ácido cis-3-hexenóico, ácido trans-2-hexenóico, ácido transgeranóico, 3,7-dimetil-1,5,7-octatrien-3-ol (0,36\% a 1,24\%) e 2,6-demetil-3,7- octadieno-2,6-diol (3,36\% a $9,99 \%$ ). Os últimos dois componentes estão presentes numa concentração muito elevada ( até $1,24 \%$ e $9,99 \%$ respectivamente). 
possibilidade de expansão devido a sua topografia. Cada planta do chá rende apenas de 50 a 100 gramas, por ano, perfazendo um montante de 9 a 10 milhões de $\mathrm{Kg}$, que a região produz anualmente para o consumo, fator com que faz encarecer o produto. As práticas agrícolas de Darjeeling obedecem a um conjunto de técnicas precisas, desenvolvidas e utilizadas há 150 anos que garantem uma altura adequada para o crescimento da planta, condição necessária para a colheita, sendo que ela é feita manualmente.

A colheita em Darjeeling começa no final de Fevereiro ou início de Março e prolonga-se até meados de novembro, face às condições metrológicas, sendo que não há plantio ou colheita nos meses de Dezembro e Janeiro pela baixa temperatura do ambiente. As técnicas usadas para a colheita do chá são transmitidas de geração para geração, feitas normalmente por mulheres, pela a exigência da manipulação delicada nas folhas frescas, para garantir e conservar sua qualidade.

Após a colheita as folhas passam por um processo de transformação (secagem, seleção, classificação e embalagem) denominada "método de Darjeeling", nas fabricas que ficam situadas exclusivamente na área de plantio, não sendo feita nenhuma etapa do processo de seleção fora da área das plantações de chá.

A primeira etapa da produção do "Método de Darjeeling" consiste em submeter à folha do chá, a um processo de "seca" que objetiva provocar a lenta evaporação da umidade das folhas, levando um período de 14 a 16 horas. As folhas verdes são separadas e espalhadas uniformemente em câmaras de ar - que permitem a passagem de ar de forma controlada- até que se obtenha a "secagem" pretendido, havendo aproximadamente uma perca de $75 \%$ do teor de água por meio de evaporação. No final desse processo a folha encolhe e torna-se macia, propícia para suportar a torção e o enrolamento mecânico, momento em que começam a desenvolverem-se as características do chá, devido suas alterações físicas e químicas na estrutura da folha.

As folhas secas retiradas das câmaras são postas em máquinas, cuja função é enrolar a folha do chá, que sob a pressão e a torção as folhas rompem as células que liberam os sucos naturais, facilitando a oxidação e aceleração da pigmentação. Em seguida, elas são postas em outra câmara, esta com a função de ventilar a folha para que possa haver lentamente a oxidação (fermentação). Nessa fase os flavonoides se misturam com o oxigênio, num período de 2 a 4 horas, decorre em função da temperatura ambiente e da umidade do ar uma fragrância progressivamente liberada da pela folha do chá. O controle dessa etapa da produção é feita por um funcionário da fabrica a partir da fragrância exalada da planta.

No último estágio do preparo as folhas oxidadas passam por um processo de desativação das enzimas e remoção de qualquer resquício de umidade. A s folhas oxidadas passam por uma corrente de ar quente, com duração entre 20 e 30 minutos, tendo o produto final menos de $2 \%$ de taxa de umidade. Por último, o produto final é acondicionado em lotes - contem nas embalagens folhas duplas de alumínio- que mantem a qualidade chá num longo período de tempo.

O chá que será comercializado é classificado em três categorias, que são classificadas da seguinte forma:

a) Folha inteira- FTGOP- Fine Tippy Golden Flowery Orange Pekoe

b) Folha partida- TGBOP- Tippy Golden Broken Orange Pekoe;

c) Moinha- GOF- Golden Orange Fannings.

A classificação usual feito pelas fabricas de Darjeeling, tem como único objetivo a diferenciação no tamanho das folhas, não alterando a qualidade do produto. 


\section{A ATUAL DA DIRETORIA DO CHÁ NA PROTEÇÃO DE DARJEELING}

A proteção legal foi um ponto importante da atuação da Diretoria do Chá, em relação ao direito de propriedade intelectual. A Diretoria tem o seu direito alicerçado na legislação indiana sobre uso da palavra e logotipo "Darjeeling", sob a égide da Trade Marks Act, de 19997 , que asseguram os seguintes direitos: a) a palavra "Darjeeling"e o logotipo como marcas registradas e certificadas a Diretoria do Chá; o logotipo é protegido por direitos autorais e registrado como um trabalho artístico. A palavra "Darjeeling" e seu logotipo foram as primeiras indicações geográficas registradas na Índia. A lei que protege os Indicadores Geográficos naquele país foi promulgada por uma motivação obrigacional, nos ternos do Acordo TRIPS (Agreement on TradeRelated Aspects of Intellectual Propety Rights), o qual exige que os membros da Organização Mundial do Comércio, devem implementar legislação pertinente à proteção de Indicador Geográfico.

O Conselho do Chá é o único representante dos produtores de chá da Índia, cabendo ao Conselho à implantação de regulamentos e políticas de governo. Ele é investido de autoridade para administrar todas as fases do chá, do cultivo até o processamento e comercialização. Da relação entre o Conselho e Associação dos Plantadores de Darjeeling (Darjeeling Planters Association) nasceram as diretrizes básicas para a comercialização do chá produzido em Darjeeling, formados basicamente por quatro objetivos principais: a) evitar o uso indevido da palavra " Darjeeling" para o chá vendido em todo o mundo; b) assegurar a qualidade do produto para o consumidor final; c) garantir que a equidade da marca atinja a indústria do chá indiano e os trabalhadores da plantação; d) alcançar o status internacional, semelhante ao champanhe ou uísque escocês, em termos de marca e respeitabilidade no mercado de consumo.

A estratégia elaborada pelo Conselho do chá para a proteção da marca Darjeeling em nível nacional e internacional como uma marca de certificação e indicação geográfica foi à formulação de um amplo sistema de certificação. O primeiro requisito para que haja a certificação do chá com o logotipo "Darjeeling" é a exigência que a planta tenha sido cultivada na área geográfica definida no registro da Junta do Chá; o segundo requisito é que a folha tenha sido processada em uma das fábricas localizadas na área geográfica definida no registro; e por derradeira exigência, o chá deve ser submetido aos testes aplicados pelos perito provadores de chá, cujo objetivo é verificar se as características organolépticas distintivas encontra-se presente.

O nível de certificação alcançado pelo Conselho do Chá abrange todas as fases do nível de produção, chegando até a fase de exportação, pretendendo desta forma garantir ao consumidor que o chá é genuíno da região de Darjeeling. Os licenciamentos

\footnotetext{
${ }^{7}$ Nos termos legais do Trade Marks Act de 1999, temos a seguinte redação: C. Uma indicação geográfica é violada por uma pessoa que, não sendo um usuário autorizado do mesmo: i. Usa tais indicações geográficas, por qualquer meio, na designação ou apresentação de bens que indique ou sugira que tais mercadorias são originárias de alguma outra área geográfica distinta do verdadeiro lugar de origem das mercadorias de uma forma que induza o público, ou, ii) use qualquer indicação geográfica de tal maneira que constitua um ato de concorrência desleal, inclusive se passando por indicações geográficas registradas; iii) use outra indicação geográfica para os bens que, embora literalmente verdadeira quanto ao território, região ou localidade em que as mercadorias são originárias, represente falsamente ao público que os produtos são originários da região, território ou localidade em relação às quais tais indicações geográficas registradas são relacionadas.
} 
também são aplicados aos vendedores do chá de "Darjeeling" na Índia, o programa tem como finalidade precípua manter informações sobre a produção de chá, controlando as indústrias de chá-evita haver fraude ou mistura na produção do chá- além de garantir um fornecimento genuíno do produto.

O Conselho do Chá para garantir o genuíno fornecimento do produto da região de Darjeeling criou um sistema obrigatório de certificação da autenticidade para a exportação, entrando em vigor em fevereiro de 2000. O sistema impõe o pagamento anual de uma taxa de licenciamento para todos os comerciantes da região de Darjeeling, ficando todos os produtores obrigados a aceitar o termo e as condições de acordo, o qual prevê que todas as informações relativas à produção, fabricação e venda do chá devem ser prestadas ao Conselho do Chá. Os produtores da região de Darjeeling ficam proibidos de misturar chás de outra origem, havendo uma rigorosa fiscalização pelo Conselho.

O certificado de autenticidade e qualidade do chá é emitido para remessas de exportação, sob o endosso do Tea Markentig and Distribution Control. O controle é feito pelo "The Garden Invoices", sendo o primeiro registro feito fora das fábricas de Darjeeling, contendo os dados dos produtos que saem dos fabricantes, cujos dados são armazenados em um banco de informações, onde mais tarde será feito um cruzamento com as informações entre as vendas dentro da Índia e a exportação do chá para outros países.

Esse certificado é exigido pelas autoridades aduaneiras, por força de um ato administrativo imposto pelo governo indiano, que obriga a todos os postos de aduana a fiscalizar se os produtos advindos de Darjeeling têm o certificado de origem, podendo proibir a exportação caso não haja o certificado que acompanha as remessas de chá. Esse controle assegura a integridade do produto até a remessa deixar o país. Além do esforço interno, o Conselho do Chá se esforça para conscientizar os compradores no exterior para a importância de serem exigidos os certificados de origem, para garantia do próprio consumidor.

No âmbito internacional o uso da palavra Darjeeling e o seu logotipo são protegidas como Indicações Geográficas na Índia, tendo também proteção no Reino Unido, EUA e Índia por meio de Certificação de Marcas. Um grande desenvolvimento na área do registro da palavra "Darjeeling" foi o reconhecimento como marca coletiva pela União Europeia, publicada no Diário Oficial da União Europeia, no dia 21 de Outubro de 2011, no documento denominado de Regulamento de Execução (UE) n'1050/2011 da Comissão de 20 de Outubro de 2011, conforme o Regulamento (CE) n510 /2006 do Conselho, 20 de Marco de 2006. O oitavo ponto da regulamentação do Conselho Europeu, definiu o uso do nome Darjeeling para feitos comerciais, da seguinte forma:

(8) O nome 'Darjeeling' só deve ser usado como designação comercial para o chá integralmente produzido na área geográfico em conformidade com o caderno de especificações, embora as misturas destes chá possam ser feitas dentro ou fora da área geográfica. As misturas de 'Darjeeling' como designação comercial, devendo ser rotuladas em conformidade com as regras da União nesta matéria, nomeadamente para evitar induzir os consumidores em erro. ${ }^{8}$

\footnotetext{
${ }^{8}$ http://eur-lex.europa.eu/LexUriServ/LexUriServ.do?uri=OJ:C:2009:246:0012:0016:PT:PDF
} 
Nessa constância protetiva o Conselho do Chá, conseguiu registrar a proteção do logotipo "Darjeeling" na Bélgica, Holanda, Luxemburgo, Alemanha, Áustria, Espanha, França, Portugal, Itália, Suíça, antiga Iugoslávia, Egito e Líbano como uma marca coletiva. Junto com o esforço de registrar e proteger legalmente no âmbito internacional a palavra e o logotipo "Darjeeling", o Conselho também assumiu a responsabilidade para denunciar, abusos de empresas estrangeiras, que indevidamente faz uso não autorizado do nome ou tenta registrar logotipo do chá de Darjeeling. Antes de ingressar num processo litigioso, o Conselho indiano do chá tenta realizar uma negociação amigável com as empresas, embora pouco exitosa as tratativas, há casos em que empresas estrangeiras com o auxilio do seu respectivo governo, foram resolvidos sem a necessidade de haver litígio.

\section{OS DESAFIOS DO CHÁ DE DARJEELING}

\subsection{CASO JAPÃO}

As dificuldades encontradas pelo Conselho do Chá indiano na proteção e fiscalização, para não haver o uso indevido da palavra e logotipo da palavra "Darjeeling" por empresas estrangeiras, têm se demonstrado um desafio, especialmente pela falta de complacência dos países de origem das respectivas empresas. Uma série de obstáculos e dificuldades na proteção está relacionada a países como Japão, França, Rússia.

Um dos países mais emblemáticos entre os citados é o Japão, pela frequência que empresas japonesas fazem o uso indevido da palavra, do logotipo ou até mesmo da tentativa de registrar a marca "Darjeeling", sem o devido respaldo legal da legislação japonesa. O primeiro exemplo, do uso não autorizado e registro da palavra e logotipo no Japão, trata de ação judicial impetrada pelo Conselho do Chá contra a empresa japonesa International Tea KK, para invalidar o registro de 29 de Novembro de 1996, sob o $\mathrm{n}^{\circ}$ 3221237, registrado no Japanese Patent Office (JPO), com o seguinte logotipo: Darjeeling Woman 'serving tea/coffe/coca/soft drinks/fruit juice.

A base argumentativa do Conselho do Chá, referente ao objeto de impugnação do registro da empresa japonesa, tinha como fundamento, a apresentação do registro $\mathrm{n}^{\mathbf{o}}$ 2153713, datado de 31 de Julho de 1987, que apresentava como escopo, a proteção do logotipo idêntico usado pela empresa japonesa. Contra a mesma empresa japonesa, o Conselho ajuizou ação de anulação de registro, sendo que o Conselho da Japanese Patent Office (JPO), analisando o recurso apresentado, considerou no dia 28 Agosto de 2002, que o registro da empresa era inválida, usando como argumento que o registro "pirata" era contra a ordem pública e contra a moralidade. Como a empresa International Tea KK, segundo o Conselho da Japanese Patent Office, não forneceu provas suficientes para justificar a utilização do registro, o pedido do Conselho do Chá indiano obteve êxito. 
O segundo caso apresentado, refere-se a um pedido de invalidação de registro, contra a empresa japonesa Mitsui Norin KK, em 29 de Fevereiro de 2000, em desfavor ao uso da expressão "Darjeeling Divine". A argumentação apresentada à oposição do uso do termo Divino Darjeeling, tinha como escopo três considerações : a) Divina é um termo elogioso (não sendo distintivo), não havendo ressalva sobre o uso do termo, mas a o que se buscava, somente era a busca da proteção do uso do nome "Darjeeling"; b) "Darjeeling Divino" trazia, segundo o argumento a presentado pelo Conselho do Chá, em certo sentido, pelo fato da empresa japonesa oferecer ao mercado consumidor café e cacau, e no distrito de Darjeeling não produz nenhum dos produtos ofertados, podendo desta forma, levar o consumidor a erro; c) o chá de "Darjeeling" é um Indicador Geográfico, nos termos das convenções internacionais, devendo ser protegida pelo Japão, por ser este país membro da OMC.

A oposição apresentada pelo Conselho do Chá, seguida do pedido de invalidação, foi analisada pelo Japanese Patent Office, que se manifestou contrário aos argumentos do Conselho indiano, entendendo que a marca "Darjeeling Divine", como um todo, não era enganosa ou descritiva na qualidade dos produtos. Entretanto, o pedido de cancelamento do direito de uso da marca foi exitoso, por não ter a empresa japonesa conseguido provar a titularidade do registro, e consequentemente o direito de uso da marca no Japão.

Situação semelhante ao caso "Darjeeling Divine" em que a empresa japonesa só ficou desfavorecida, por não ter provado e nem trazido evidências suficientes, que tinham o registro no escritório de patentes do Japão, onde constasse a autorização do uso da marca, esse caso foi uma ação proposta pelo Conselho do Chá contra a empresa japonesa Yutaka Sangyo Kabushiki Kaisa, com o argumento que a empresa japonesa estava sendo contrária à ordem pública e à moral. $\mathrm{O}$ pedido foi indeferido, com $\mathrm{o}$ fundamento que os caracteres escritos em inglês "Chá de Darjeeling" e o uso do mapa da Índia, são indicadores de origem, não feridos "os sentimentos da população indiana". O Conselho do Chá conseguiu que a empresa perdesse o Direito de uso da palavra "Darjeeling", porque a empresa japonesa não provou que tinha registrado para o uso da palavra no Japão.

As decisões expedidas pela Japanese Patent Office (JPO) não respeitam os Acordos TRIPS, o qual exige que os membros da OMC (o Japão é membro) devem fornecer os meios legais necessários para impedir a utilização de um Indicador Geográfico, coibindo a concorrência desleal e o induzimento do consumidor ao erro.

\subsection{CASO FRANÇA}

O sistema legal indiano protege os produtos (Indicadores Geográficos) franceses, mas a recíproca não é verdadeira, não havendo subsídio por parte do sistema jurídico francês aos produtos indianos. A lei francesa não coloca óbice a uma proposta de concessão de marca semelhante ou até mesmo idêntica ao de um Indicador Geográfico, se os produtos abrangidos são diferentes daqueles representados pelo IG. O detentor do registro da IG na França poderá ter acesso a instrumentos jurídicos apropriados, mas somente após a concessão do pedido de registro da parte pleiteante.

A Le Examiner Francesa analisando empresas vendedoras de produtos para vestuários (roupas, sapatos, chapéus, etc.) que usavam como atrativo para a venda de seus produtos o nome “ Darjeeling”, após reclamação da Diretoria do Chá da Índia, chegou a seguinte conclusão: a) Mesmo com as evidências encontradas a favor da Diretoria do Chá de Darjeeling, não há prova suficiente do uso do termo "Chá de Darjeeling" na França; b) o pleito sobre o uso do nome "Darjeeling" não deveria 
prosperar, porque mesmo que haja o uso da nome, a natureza, função e uso pretendido dos produtos, os mesmos são distintos, além de serem produzidos em regiões diferentes e vendidos através de redes diferentes. Encerrou a conclusão afirmando que a diferença da natureza dos respectivos bens é suficiente para manter a marca das empresas francesas, não havendo prejuízo aos direitos da Diretoria do Chá de Darjeeling, terminando a afirmação, conferindo legitimidade a adaptação do nome "Darjeeling" para produtos de natureza diferente ao do chá.

O caso da empresa francesa Dor François-Marie, ilustra bem a posição da Le Examiner Francesa, referente ao uso da marca de IG em produtos de naturezas diferentes. A empresa François-Marie reproduzia parcialmente o logotipo do Chá de Darjeeling, em vários produtos de sua linha. O Conselho do Chá apresentou oposição, e a após ser examinada a oposição. A Le Examine chegou à conclusão que mesmo havendo uma reprodução parcial do logotipo do chá, os produtos não eram de mesma natureza, função e uso pretendido, também não compartilham o mesmo circuito de distribuição, não havendo desta forma prejuízo ao produto de Darjeeling.

O Conselho do Chá da Índia tenta entrar em acordo com as empresas estrangeiras antes de procurar os meios legais. Com a mentalidade voltada para a mediação e a arbitragem, o Conselho do Chá com ajuda do governo indiano, tenta negociar com o governo francês em vários níveis burocráticos sobre as atividades comerciais das autoridades de marcas francesas. O "caso Bulgari, Suíça" é um dos exemplos de sucesso, entre o Conselho de Chá e empresas estrangeiras, no citado caso, a empresa por meio de aviso legal e negociações, concordou em retirar do mercado a legenda "Darjeeling Tea fragrância para homens".

Situação inusitada foi a da empresa Comptoir des Parfums (França), que anunciou em Março de 1999, o interesse de registrar sua marca com o nome "Darjeeling", sobre o anunciado o Conselho do Chá resolveu mandar uma correspondência à empresa, chamando atenção para os direitos de marca do Chá de Darjeeling, e pedindo que fosse-se retirado à intenção do registro com o nome "Darjeeling" de forma voluntária. Com base da na correspondência ( que alertava sobre a boa vontade) a empresa francesa retirou sua intenção de forma voluntária.

\section{A RELEVÂNCIA DO REGISTRO DA PROPRIEDADE PARA PERPETUAÇÃO DE MARCAS}

Em relação a este tópico, é de se dizer que, muito embora o enfoque do presente estudo tenha sido a relação entre países que pleiteiam o uso de um produto em comum, não se pode olvidar que, no Brasil, a liberdade de expressão é garantida pela Constituição de 1988, principalmente nos incisos IV e IX do artigo $5^{\circ}$. Enquanto o inciso IV é mais amplo e trata da livre manifestação do pensamento, o inciso IX foca na liberdade de expressão da atividade intelectual, artística, científica e de comunicação.

Ademais, a Carta Magna, ainda no seu artigo $5^{\circ}$, que, frise-se: trata dos direitos e deveres individuais e coletivos, estabelece o direito à proteção das criações intelectuais:

Inciso XXVII - aos autores pertence o direito exclusivo de utilização, publicação ou reprodução de suas obras, transmissível aos herdeiros pelo tempo que a lei deixar.

Inciso XXIX - a lei assegurará aos autores de inventos industriais privilégio temporário para utilização, bem como proteção às criações industriais, à propriedade das marcas, aos nomes de empresas e a outros signos distintos, tendo em vista o nteresse social e o desenvolvimento tecnológico e econômico do País. 
Os direitos autorais, por seu turno, dizem respeito mais a questões criativas, tais como obras do espírito criativo, obras arquitetônicas, artes plásticas, literárias e audiovisuais, formando o patrimônio intelectual, protegido igualmente.

Em conformidade com o Manual Propriedade Industrial da Associação Brasileira da Indústria de Máquinas e equipamentos - ABIMAQ/IPD-Maq: " $A$ Propriedade Industrial é o ramo da Propriedade Intelectual que trata das criações intelectuais voltadas para as atividades de indústria, comércio e prestação de serviços e engloba a proteção das invenções (patente de invenção e modelo de utilidade), desenhos industriais, marcas, indicações geográficas, bem como a repressão da concorrência desleal". ${ }^{9}$

No que concerne às relações internacionais que o Brasil firma no âmbito da proteção à propriedade intelectual, é de se registrar que, ao lado de todo um arcabouço legislativo, também os Tratados Internacionais exercem papel relevante.

Quando registrada no Brasil, por intermédio do INPI, o proprietário adquire o direito de uso exclusivo em todo o Brasil, podendo tal direito ser estendido para mais 137 países. Isso acontece, pois, o Brasil faz parte da Convenção da União de Paris (CUP), acordo internacional relativo à propriedade Intelectual.

Referida Convenção teve seu início sob a forma de anteprojeto, redigido em uma Conferência Diplomática realizada em Paris no ano de 1880, tendo entrado em vigor, com o texto definitivo, em 7 de julho de 1883.

O Brasil, país signatário original, aderiu à Revisão de Estocolmo em 1992.

Estabelece a CUP, em seu artigo 14, que o País que tiver depositado um pedido de patente em um dos países da união, poderá apresentar seu pedido para a mesma matéria nos outros países dentro do prazo de 12 meses, gozando do direito de prioridade.

Dessa forma, o documento não será invalidado por atos realizados durante o mesmo período, tais como o depósito por outra pessoa ou publicação de exploração de uma invenção.

Há ainda um outro importante pacto firmado internacionalmente acerca dos direitos que envolvem a propriedade intelectual que foi o Protocolo de Madri, cujo instrumento é um tratado internacional vinculado à Organização Mundial da Propriedade Intelectual (OMPI). O documento permite que o titular de determinada marca, desde que pertença a um dos países membros do acordo, possa replicar o seu pedido para qualquer outro país membro, sem a necessidade de realizar depósito individual em cada um deles, minimizando custos e burocracia.

A adesão do Brasil ao Protocolo de Madri é recente, tendo ocorrido por intermédio do Decreto Legislativo $\mathrm{n}^{\circ} 49$, publicado no Diário Oficial da União de 30/05/2019. 
De um modo geral, sem dúvida a relevância da propriedade intelectual para a perpetuação e proteção das marcas é muito grande, não somente no que toca à preservação do processo inventivo, mas especialmente como um elemento propagador da vida financeira e da imagem das companhias.

Dito de outro modo, a possibilidade de registro de marcas, em níveis globais, viabiliza o trânsito de criações intelectuais e a sua exploração dos mais diferentes setores do planeta.

\section{CONCLUSÃO}

Os custos relacionados com as despesas legais, registro, e contratação de agências internacionais de vigilância, com o fim de combater infrações relacionados à palavra e o logotipo "Darjeeling", têm onerado o Conselho do Chá em \$200,000.00 (Duzentos mil dólares) nos últimos quatro anos. Nestas despesas não estão inclusas o salário de funcionários, custeio administrativo, desenvolvimento de softwares (com a finalidade de controle) e criação de mecanismos de controle do uso da marca. Os custos que o titular de uma Indicação Geográfica está sujeito, incluindo advogados, medidas legais, acompanhamento e execução da proteção do IG, são tão altos, que mesmo ocorrendo um abuso, alguns titulares não pleiteiam judicialmente por falta de condições financeiras.

Os custos arcados pelo Conselho do Chá, devido à política implantada pelas autoridades de patentes dos governos da França e Japão, levaram a Índia e outros países membros da OMC proporem um sistema onde o registro do IG estende-se a produtos e mercadorias, cujo sistema teria que respeitar as características essencialmente atribuíveis à origem geográfica de determinado produto, não podendo fazer uso da imagem ou marca. Outro ponto da proposta é o desenvolvimento de um sistema multilateral de notificação e registro de todas as Indicações Geográficas. Neste contexto, um documento conjunto foi recentemente submetido ao Two's TRIPS Council; a Declaração de Doha nos termos dos artigos 12 e 18 visa proporcionar um nível mais elevado de proteção aos Indicadores Geográficos, que deverá ser abordado pelo Conselho TRIPS.

O problema enfrentado pelo chá indiano na França e no Japão está ligado à falta de unicidade legal. A proteção dada pela legislação indiana a produtos estrangeiros não recebe a mesma reciprocidade em outros países, como por exemplo, a legislação francesa, que permite o pedido de registro, sem a possibilidade de haver oposição de terceiros, garantida legalmente apenas a efetivação do registro pela empresa proponente. A legislação japonesa não se atém à proteção de marcas internacionais, focando apenas na proteção em sentido estrito, não apreciando todas as variáveis que o uso indevido possa acarretar, sendo faltosa em uma proteção mais ampla, como se pôde verificar no caso "Devine Darjeeling".

Releva também concluir a respeito da importância de haver regras claras quanto às normas de registro das Indicações Geográficas (IG), pois há muitas regiões que concentram expertises e conhecimentos - milenares, em alguns casos - sobre determinado serviço ou produto. Ou seja, a preservação desta propriedade intelectual parece ser um interesse global, haja vista que, com isso, buscar-se-á preservar algo além 
do um interesse comercial, negocial, mas sim de toda uma cultura, algo muitas vezes intangível, mas nem por isso menos sujeita à violações.

As experiências advindas do embate entre o Conselho do Chá e empresas japonesas e francesas demonstram a necessidade de evoluir no tocante à proteção de registros IG, não devendo ser permitido o registro de uma marca/produto com características semelhantes à de um IG já registrado. Deve-se negar inclusive a intenção do registro, publicando tanto em nível nacional como internacional, com o intuito de coibir uma possível tentativa de um novo pedido de registro, por meio de precedentes. Além destas medidas, o desenvolvimento de regras e procedimentos únicos, tanto para o registro de marcas e patentes, como mecanismo de defesa legal protetivo, a todos os membros da OMC. Essas providências iriam impedir, ou pelo menos diminuir, os conflitos jurídico envolvendo marcas e patentes.

Por último, a criação de um órgão de vigilância, objetivando verificar a violação e /ou abusos no tocante a produtos protegidos por Indicação Geográfica.

\section{REFERÊNCIAS}

AMARAL, Rentada Vargas. "Retaliação cruzada em propriedade intelectual: instrumento de efetivação do sistema de solução de controvérsias da Organização Mundial do Comércio (OMC)?”. In: Pimentel, Luiz Otávio (org.). Eficiência Energética, Inovação e Propriedade Intelectual. Florianópolis: FUNJAB, 2013.

ARANTES NETO, Adelino. Responsabilidade do Estado no Direito Internacional e na OMC. $22^{\mathrm{a}}$. ed. Curitiba: Ed. Juruá Editora,2007.

BIACCHI GOMES, Eduardo. Manual de Direito da Integração Regional. 2a . ed. Curitiba: Ed. Juruá Editora,2012.

CRUCINI, Mario J; Kahn, James. Tariffs and aggregate economic activity: lessons from the great depression. Journal of Monetary Economics. Ed. Elserver. V. 38. Issue 3, 1996,P. $246 \quad-\quad$ 467.Disponível em: <http://www.sciencedirect.com/science/article/pii/S0304393296012986>. Acesso em: 27/07/2018.

Disponível

em: $<$ http://eurlex.europa.eu/LexUriServ/LexUriServ.do?uri=OJ:C:2009:246:0012:0016:PT:PDF>. Acessado em: 13/05/2018.

Disponível

em: $<$ http://eurex.europa.eu/Result.do? $\arg 0=$ Darjeeling $\& \arg 1=\& \arg 2=\&$ titre $=$ titre $\&$ chlang $=$ pt $\&$ RechT ype=RECH_mot\&Submit=Pesquisar $>$. Acessado em: 13/05/2018.

Disponível

em: $<$ http://eurex.europa.eu/LexUriServ/LexUriServ.do?uri=OJ:L:2011:276:0005:0012:PT:PDF>.Ace ssado em :15/05/2018. 
Disponível em: < http://www.wto.org/index.htm>. Acessado em: 15/05/2018.

Disponível em: <http://www.teaboard.gov.in/> . Acessado em: 15/05/2018.

Disponível em : <http://ipindia.nic.in/tmr_new/tmr_act_rules/TMRAct_New.pdf $>$. Acessado em: 15/05/2018.

Disponível em: <http://www.lawzonline.com/bareacts/trade-and-merchandise-marksact/trade-and-merchandise-marks-act.html >. Acessado em: 15/05/2018.

Disponível em: $<\mathrm{http}: / /$ www.teaboard.gov.in/inner1.asp?param_link_id=170\&mem_link_name=170>. Acessado em: 15/05/2018.

Disponível em: <http://www.wto.org/english/res_e/booksp_e/casestudies_e/case16_e.htm>. Acessado em: 25/05/2018.

Disponível em:

http://www.abimaq.org.br/Arquivos/Html/IPDMAQ/10\%20Propried\%20Ind,\%20Manu al\%20-\%20IPDMAQ.pdf. Acessado em: 01/04/2020 às 11:04 h.

DUPUY, Pierre-Marie. Le Fait Générateur de La Responsabilité Internationale des États. RCADI, v.188,1984. p.9-134.

GANDELMAN, Maria. $1^{\text {a }}$. ed. Poder e Conhecimento na Economia Global: O Regime Internacional da Propriedade Intelectual da Sua Formação às Regras de Comércio Atuais. Rio de Janeiro: Ed. Civilização Brasileira, 2004.

GONÇALVES, Reinaldo; Baumann, Renato; Canuto, Otaviano; C. D. Prado, Luiz. A Nova Economia Internacional: Uma Perspectiva Brasileira. 9a ${ }^{a}$ ed. Rio de Janeiro: Ed. Campus, 1998.

INSTITUTO NACIONAL DA PROPRIEDADE INTELECTUAL. Apresenta o Decreto $\mathrm{n}^{\mathrm{a}}$ 1. 355, de dezembro de 1994, cujo apenso trás o Acordo Sobre Aspectos dos Direitos de Propriedade Intelectual Relacionados ao Comércio. Disponível em: <www.inpi.gov.br/images/stories/27-trips-portugues1.pdf>. Acesso em: 15/08/2014.

POSSA, Ana Lethea da Cunha. A eficácia jurídica da declaração universal dos direitos humanos. Revista Juridica, [S.1.], v. 20, n. 4, p. 27-48, dez. 2007. ISSN 2316-753X. Disponível em: <http://revista.unicuritiba.edu.br/index.php/RevJur/article/view/128/101>. Acesso em: 21 abr. 2020. doi:http://dx.doi.org/10.21902/revistajur.2316-753X.v20i4.128.

TACHINARDI, Maria Helena. A Guerra das Patentes: Conflito Brasil x EUA sobre propriedade intelectual. 1ª . ed. São Pauli: Ed. Paz e Terra, 1993. 